\title{
Electrodeposition of ZnO Film With Enhanced Photocatalytic Activity Towards Methylene Blue Degradation
}

\author{
Feng Zhang ${ }^{1, *}$, Wenjuan Zhang ${ }^{2}$, Xiaolin Luo ${ }^{1}$, Guodong Feng ${ }^{1}$ and LiFang Zhao ${ }^{1}$ \\ ${ }^{1}$ Key laboratory of Advanced molecular engineering materials; Department of Chemistry and \\ Chemical Engineering, Baoji University of Arts and Science, Baoji, Shaanxi, 721013, P.R. China \\ ${ }^{2}$ Department of Electrical Engineering, Baoji University of Arts and Sciences, Shaanxi, 721013, P.R. \\ China \\ *E-mail: bj_zhangfeng@yeah.net
}

doi: $10.20964 / 2017.05 .62$

Received: 14 February 2017 / Accepted: 8 March 2017 / Published: 12 April 2017

\begin{abstract}
A moderate electrodeposition synthesis was developed in this work to prepare a $\mathrm{ZnO}$ film. The target of this research is to determine the best photoelectrochemical response for solar-induced water decomposition. On the basis of the acquired results, a nanostructured $\mathrm{ZnO}$ film was developed on the surface of a substrate. The photocatalytic and photoelectrochemical responses of the obtained wurtzitetype $\mathrm{ZnO}$ film were monitored and assessed for comparison with those of the commercial $\mathrm{ZnO}$. In respect to the newly formed $\mathrm{ZnO}$ thin film, light current densities of $17.14 \mathrm{~mA} / \mathrm{cm}^{2}$ under ultraviolet light and $13.71 \mathrm{~mA} / \mathrm{cm}^{2}$ under visible light were observed. The $\mathrm{ZnO}$ film was believed to possess excellent capacity to absorb more incident photons from the illumination to produce more photoinduced charge carriers, giving rise to the photocatalytic and photoelectrochemical reactions. In addition, incident rays from any orientation can be caused by light-scattering effects and the high specific surface area of 2D nanostructures.
\end{abstract}

Keywords: Electrodeposition; ZnO; Photocatalysis; Thin film; Methylene blue; Organic waste

\section{$\underline{\text { FULL TEXT }}$}

(C) 2017 The Authors. Published by ESG (www.electrochemsci.org). This article is an open access article distributed under the terms and conditions of the Creative Commons Attribution license (http://creativecommons.org/licenses/by/4.0/). 